\title{
DISTRIBUTION OF ADENOSINETRIPHOSPHATASE ACTIVITY IN RAM AND BULL SPERMATOZOA
}

\author{
P. J. QUINN* AND I. G. WHITE \\ Department of Veterinary Physiology, University of Sydney, Sydney, Australia
}

(Received 23rd September 1967)

The active transport of sodium and potassium has been demonstrated in dog spermatozoa (Quinn \& White, 1967) and the existence of a cation pump, involving a sodium-potassium activated ATPase has been postulated to account for the gradients of alkali metal ions between the cell and seminal plasma (Quinn, White \& Wirrick, 1965). Recently, Uesugi \& Yamazoe (1966) have reported the occurrence of a sodium-potassium activated ATPase in boar epididymal spermatozoa, and the present experiments were undertaken to determine the activity and distribution of ATPases in ram and bull spermatozoa.

Semen was diluted with $2.5 \mathrm{vol}$ of $250 \mathrm{~mm}$-sucrose, centrifuged, and the spermatozoa washed twice with 5-ml aliquots of sucrose. Washed spermatozoa, resuspended in sucrose buffered to $\mathrm{pH} 7.4\left(37^{\circ} \mathrm{C}\right)$ with 50 mM-tris (tris [hydroxylmethyl] amino methane) and $40 \mathrm{~mm}-\mathrm{HCl}$ were incubated with $3 \mathrm{~mm}$ ATP which was rendered free of cations by eluting the disodium salt (Sigma Chemical Co.) through a column of Zeo Carb $226\left(\mathrm{H}^{+}\right)$and restoring the eluate to $\mathrm{pH} 6.8$ with tris. The mixture was incubated at $37^{\circ} \mathrm{C}$ with combinations of $3 \mathrm{~mm}$-magnesium, $150 \mathrm{~mm}$-sodium and $30 \mathrm{~mm}$-potassium chlorides. After 30 min cold trichloroacetic acid was added to give a final concentration of $10 \%(\mathrm{w} / \mathrm{v})$, the precipitate was centrifuged down at $0^{\circ} \mathrm{C}$ and the phosphorus liberated (difference between 0 and 30 min incubation) measured in the supernatant (Fiske \& Subba Row, 1925). Checks showed that this was linear for at least up to $60 \mathrm{~min}$.

Both ram and bull spermatozoa exhibited high ATP-splitting activity (Experiment 1, Table 1) in contrast to the last wash fluid from the spermatozoa which had no activity. The activity of the magnesium-dependent ATPase was about $30 \%$ higher in whole bull spermatozoa than in ram spermatozoa, and the ATPase activity in the presence of both sodium and potassium was also correspondingly higher in the bull. There was only a slight stimulation of magnesium-dependent ATPase in the presence of either sodium or potassium. When both sodium and potassium were included, ATPase activity increased by $50 \%$ over the basal rate, which suggests that a considerable proportion of the ATP is expended in cation transport. The inhibition of cation activation by ouabain parallels a similar effect on the active transport of sodium and potassium by dog spermatozoa (Quinn \& White, 1967). Although the ATPase

\footnotetext{
* Present address: A.R.C. Institute of Animal Physiology, Babraham, Cambridge.
} 


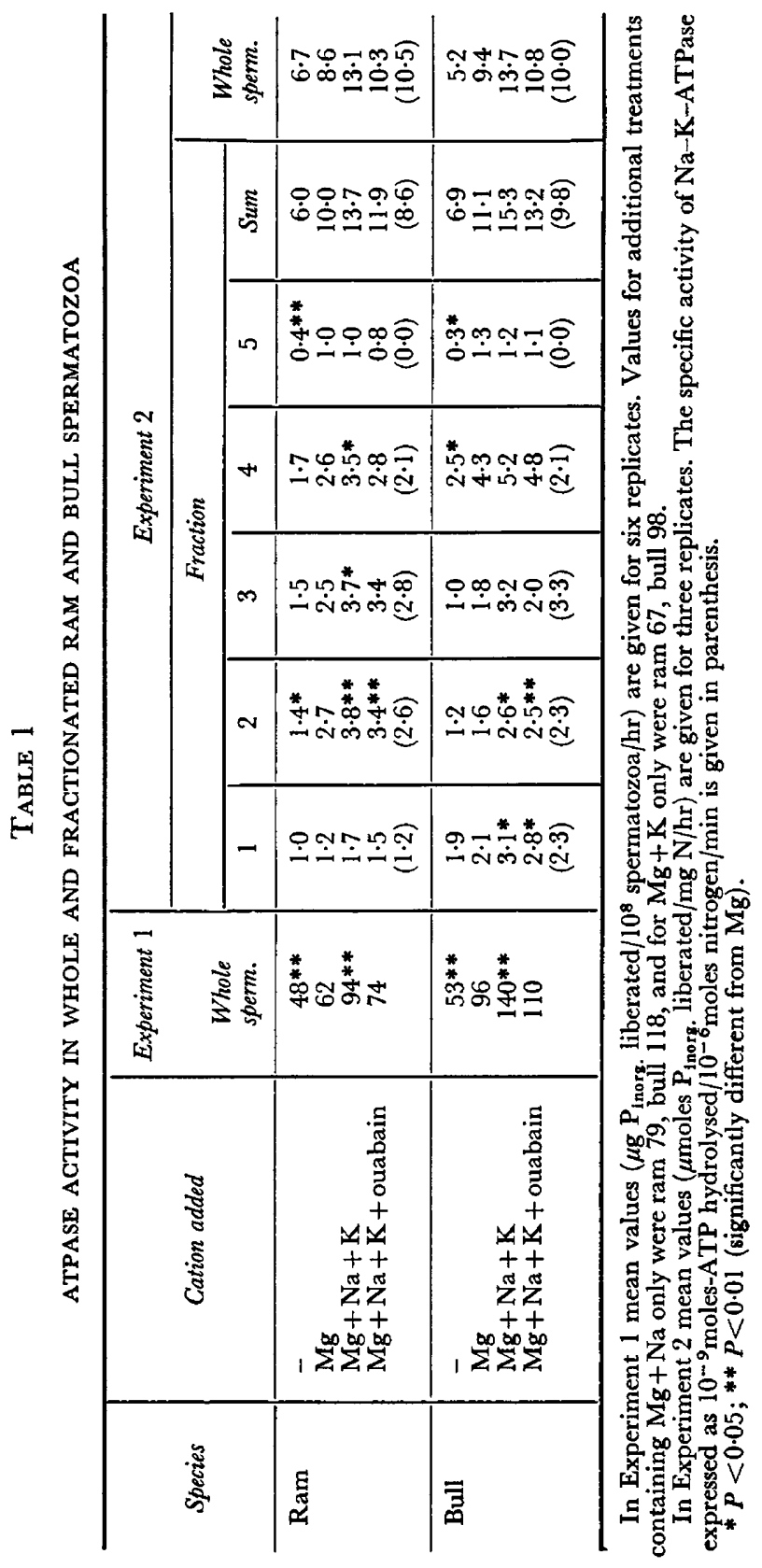


activities are twenty to thirty times higher than in epididymal boar spermatozoa (Uesugi \& Yamazoe, 1966), the relative activities of magnesium-dependent and cation-activated ATPase are similar. Using the methods outlined by Voglmayr, Scott, Setchell \& Waites (1967) the chief product of ATP breakdown has been shown to be ADP. Some AMP, however, was also formed.

A second experiment was undertaken to determine the location of ATPases in sonically disintegrated and fractionated ram and bull spermatozoa. For this experiment the washed spermatozoa were resuspended in tris-buffered sucrose containing $1 \mathrm{~mm}$-ethylenediamine-tetra-acetic acid and disintegrated for 3 $\mathrm{min}$ at 20 kilocycles/sec in a Mullard Ultrasonic vibrator. The sonicate was centrifuged at $2000 \mathrm{~g}$ for $15 \mathrm{~min}$ and the plug resuspended in $10 \mathrm{ml}$ trisbuffered sucrose, centrifuged again and separated into two fractions-the heavier Fraction 1 consisting mainly of heads and the lighter Fraction 2 containing predominantly mid-pieces (Mohri, Mohri \& Ernster, 1965). The pooled sonicate supernatants were centrifuged at $10,000 \mathrm{~g}$ for $10 \mathrm{~min}$ and the plug consisting of tail fragments and heavy microsomes was resuspended in trisbuffered sucrose (Fraction 3). The supernatant was further centrifuged at $150,000 \mathrm{~g}$ for $45 \mathrm{~min}$ and the plug (Fraction 4) containing microsomal fragments resuspended in tris-buffered sucrose. Fraction 5 was the soluble supernatant. The identity of the subcellular fractions was checked by photomicroscopy, ATPase activity assayed as for whole cells and protein estimations made by the method of Wales, Scott \& White (1961).

The magnesium-dependent ATPase activity predominated in the midpiece, tail and microsomal fractions, with lowest activity in the head. There was a similar distribution of sodium-potassium activated ATPase which, however, was most active in the tail. Ouabain inhibited the cation-activated ATPase of all fractions but the overall inhibition was less than in the whole cells.

The magnesium-dependent ATPase has been shown to be confined almost exclusively to the midpiece and tail of spermatozoa (Nelson, 1954; Mohri, 1964), and to be intimately concerned with the contractile processes of the flagella (see Bishop, 1962). Cation-activated ATPase in the tail could coordinate flagellar contractile processes. This co-ordination is absent in glycerolextracted spermatozoa models (Bishop \& Hoffmann-Berling, 1959) which can hydrolyse ATP in the presence of magnesium to produce oscillatory motion but do not have an operative cation transport mechanism because membrane permeability has been disrupted by the extraction procedure.

The authors are indebted to Professor C. W. Emmens for his interest and to Mr J. K. Voglmayr for his assistance. The work has been aided by grants from the Australian Dairy Produce Board and one of us (P.J.Q.) was supported by a Royal Agricultural Society (N.S.W.) Fellowship.

\section{REFERENCES}

Bishop, D. W. (1962) (Ed.) Spermatozoan motility. Am. Assoc. Adv. Sci., Washington, D.C.

Bishop, D. W. \& HofFMANn-BerLing, H. (1959) Extracted mammalian sperm models. I. Preparation and reactivation with adenosine triphosphate. $\mathcal{F}$. cell. comp. Physiol. 53, 445. 
Fiske, C. H. \& SubBa Row, Y. (1925) The colorimetric determination of phosphorus. 7. biol. Chem. 66, 375.

MoHri, H. (1964) Extraction of ATPase from sea urchin and fish sperm tails. Biol. Bull. mar. biol. Lab., Woods Hole, 127, 381 .

Mohri, H., Mohri, T. \& Ernster, L. (1965) Isolation and enzymic properties of the midpiece of bull spermatozoa. Expl Cell Res. 38, 217.

NeLson, L. (1954) Adenosinetriphosphatase activity of spermatozoa. Biol. Bull. mar. biol. Lab., Woods Hole, 107, 301 .

QuinN, P. J. \& White, I. G. (1967) Active cation transport in dog spermatozoa. Biochem. F. $104,328$.

QuinN, P. J., White, I. G. \& WirRick, B. R. (1965) Studies of the distribution of the major cations in semen and male accessory secretions. 7. Reprod. Fert. 10, 379.

Uesugi, S. \& Yamazoe, S. (1966) Presence of sodium-potassium-stimulated ATPase in boar epididymal spermatozoon. Nature, Lond. 209, 403.

Wales, R. G., Scott, T. W. \& White, I. G. (1961) Biuret reactive materials in semen. Aust. J. exp. Biol. med. Sci. 39, 455.

Voglmayr, J. K., Scott, T. W., Setchell, B. P. \& Wartes, G. M. H. (1967) Metabolism of testicular spermatozoa and characteristics of testicular fluid collected from conscious rams. $\mathcal{J}$. Reprod. Fert. 14,87 . 